\title{
QUEEN'S
UNIVERSITY
BELFAST
}

\section{Impact of maternal stress and nutrition on behavioural and physiological outcomes in young lambs}

Rooke, J. A., Arnott, G., Dwyer, C. M., \& Rutherford, K. M. D. (2017). Impact of maternal stress and nutrition on behavioural and physiological outcomes in young lambs. Animal Welfare, 26(4).

https://doi.org/10.7120/09627286.26.4.403

\section{Published in:}

Animal Welfare

\section{Document Version:}

Peer reviewed version

Queen's University Belfast - Research Portal:

Link to publication record in Queen's University Belfast Research Portal

\section{Publisher rights}

() 2017 Universities Federation for Animal Welfare.

This manuscript is distributed under a Creative Commons Attribution-NonCommercial-NoDerivs License

(https://creativecommons.org/licenses/by-nc-nd/4.0/), which permits distribution and reproduction for non-commercial purposes, provided the author and source are cited.

\section{General rights}

Copyright for the publications made accessible via the Queen's University Belfast Research Portal is retained by the author(s) and / or other copyright owners and it is a condition of accessing these publications that users recognise and abide by the legal requirements associated with these rights.

\section{Take down policy}

The Research Portal is Queen's institutional repository that provides access to Queen's research output. Every effort has been made to ensure that content in the Research Portal does not infringe any person's rights, or applicable UK laws. If you discover content in the Research Portal that you believe breaches copyright or violates any law, please contact openaccess@qub.ac.uk. 
1 Impact of maternal stress and nutrition on behavioural and physiological outcomes in

2 young lambs

3

JA Rooket* $\dagger^{*}$ G Arnott ${ }^{\ddagger}$, CM Dwyer ${ }^{\ddagger}$ and KMD Rutherford $\ddagger$

4

$5 \quad \dagger$ Beef and Sheep Research Centre, Future Farming Systems, SRUC, West Mains Road,

6 Edinburgh, EH9 3JG, UK

$7 \$$ Animal Behaviour and Welfare, Animal and Veterinary Sciences Research Group, SRUC,

8 West Mains Road, Edinburgh EH9 3JG, UK

9

$\S$ Institute for Global Food Security, School of Biological Sciences, Queen's University Belfast, Medical Biology Centre, 97 Lisburn Road, Belfast BT9 7BL, UK

11

*Contact for correspondence: john.rooke@ @ sruc.ac.uk; tel: +44 (0) 131535 3213; fax: +44

13

(0)1315353121

14

15 Running title: Maternal stress in sheep and progeny welfare

16

Accepted by Animal Welfare, 24 $4^{\text {th }}$ March 2017

17 
Abstract

The prenatal period is of critical importance in defining how individuals respond to their environment throughout life. Stress experienced by pregnant females has detrimental effects on offspring behaviour, health and productivity. The sheep (Ovis aries) has been used as a model to inform human studies; however, in a farming context, the consequences for the lamb of stress experienced by the ewe have received less attention. The stressors that pregnant ewes are most frequently exposed to include sub-optimal nutrition and acute and chronic stressors related to husbandry and the environment. This review focuses upon the young sheep, from around 100 days old until adulthood and uses material identified from a systematic survey of the literature relating to production-relevant maternal stressors and lamb outcomes. Overall, the results demonstrated that stressors imposed upon the ewe altered progeny behavioural and physiological responses. However, detailed analysis of the literature shows several deficiencies in the field as a whole which greatly limit the ability to draw conclusions about how welfare may be affected by prenatal challenges in commercial sheep. These deficiencies included a lack of consistency in response due to the variety of both stressors imposed and responses measured. Key gaps in knowledge include the impact of ewe disease during pregnancy on outcomes for their progeny and more generally how different commercially relevant stressors interact. Furthermore, there is a need to develop a systematic series of behavioural and physiological measures that can be integrated to provide a holistic and practically applicable picture of offspring welfare.

Key words: animal welfare; sheep; gestation; stress; offspring response 
Previous research has shown that sub-optimal maternal nutrition, stress or ill health during pregnancy can affect how offspring develop before birth, with implications for their later biology (Sinclair et al 2016). In farm animals, maternal state may therefore be an important contributor to health, welfare and productivity of progeny, and paying closer attention to gestation management could contribute to improvements in these parameters on farms (Rutherford et al 2012).

The long-term consequences of changes in the fetal environment have been well-recognised since the first reports (Barker et al 1989) describing epidemiological data linking birth weight and later health in humans. In other epidemiological studies, the children born to mothers who were pregnant during the Dutch famine in 1944-1945 experienced increased incidence of inter alia, type II diabetes and cardio-vascular disease (Lumey et al 2011). Other negative human health outcomes have also been seen following stress during pregnancy (e.g. King et al 2012). These adverse effects are generally classified under the developmental origins of health and disease hypothesis (Gluckman \& Hanson 2004) and are likely mediated by epigenetic, non-Mendelian inheritance (Ford \& Long 2012). Amongst the variety of animal models used to investigate underlying mechanisms, the sheep (Ovis aries) has proved popular since it is similar to the human in respect of maternal and fetal sizes, organ development and maturity at birth (Luther et al 2005). To date, however, less emphasis has been placed upon the consequences of disturbances to the fetal environment for the health and welfare of the offspring than on end-points associated with cardio-vascular disease and diabetes. This is of increasing relevance as the current status of legislation on the welfare of fetal animals (see Campbell et al 2015 for review) does not reflect current understanding particularly in the context of postnatal consequences. 
In cattle (Bos taurus), Arnott et al (2012) identified a wide variety of stressors the dam could

67 be exposed to during gestation and which may perturb the uterine environment with adverse consequences for the subsequent welfare and health of the offspring. The stressors identified included under-nutrition, social stress imposed by management practices such as stocking density, acute stress from handling and transport and thermal stress by being maintained outside the thermo-neutral zone. Arnott et al (2012) employed the systematic review process advocated by Sargeant et al (2006) to minimize systematic and random errors in study selection. Previously, we (Rooke et al 2015) applied the approach of Arnott et al (2012) and identified stressors applied to the ewe during gestation which were practically relevant. In Rooke et al (2015), the subject material was limited (because of the large number of studies) to measurements of lamb vigour and well-being up to the age of 100 days (weaning) and therefore interpretation of lamb responses in the context of welfare was relatively straightforward. Here we focus on studies where responses were measurements of behaviour in situations which could be considered fear-inducing or studies where responses in stress physiology were reported. The age at which offspring responses were measured ranged mainly from weaning to adulthood.

In examining the literature we have adopted the hypothesis that a stressor or insult to which the ewe was exposed to during pregnancy will influence environmental responsiveness of the offspring, measured either as changes in behaviour or in hypothalamo-pituitary-adrenal (HPA) axis responsiveness, such that adverse consequences for the offspring will ensue. In the review, the term stress(or) applies to any potentially adverse event the ewe is exposed to during pregnancy and fear is defined as a reaction to the perception of actual danger as assessed by fear tests (Forkman et al 2007). 
91 Comprehensive details of the methodologies employed are given in Arnott et al (2012) and

92 Rooke et al. (2015). The following describes first, how relevant information was identified

93 and the review process for all studies (i.e. both studies reported in Rooke et al. (2015) and

94 reviewed here). Subsequently, material specific to the present review is described.

\section{Overall review process}

96

97

\section{Searches}

The online database 'ISI Web of Knowledge' was used to search the literature from 1970 as described by Rooke et al (2015). The search terms used were designed to combine words relating to sheep and to prenatal stress and final terms were (prenatal or perinatal or maternal or fetal or foetal or gestation*) and (stress or programm* or nutrition*) and (sheep or ovine or ewe*). The initial search was carried out in November 2009 and updated until July 2015. Following removal of duplicates, the initial search yielded 3669 references. After screening for relevance by inspection of title and abstract (2388 obviously irrelevant references discarded), the remaining references were examined in more detail. Studies measuring solely fetal outcomes were excluded. References were thus retained if post-natal outcomes were measured on the offspring in response to manipulation of maternal nutrition or the application of a stressor to the dam.

\section{Quality assessment}

As recommended by Sargeant et al (2006), a quality assessment of studies was made. References were selected for inclusion using the following criteria (Arnott et al 2012): treatment intervention adequately described; inclusion of a suitable control; use of a large enough sample size; appropriate statistical methods; avoidance of data repetition (e.g. where 
components of a single study are reported in several papers); exclusion of conference

114 abstracts / proceedings. Studies remaining at this point formed the raw material for detailed

115 review $(\mathrm{n}=98)$.

\section{Review process}

117 The remaining studies were first classified into the following categories according to 118 outcomes measured in offspring: welfare; birth weight / growth; reproduction; physical 119 defects; others not encompassed by the above groups. Based on the welfare-related aims of 120 the overall review process, and the relatively large number of references, a decision was 121 taken that the first two categories (welfare outcomes and birth-weight / growth) would form 122 the raw material for review. A more detailed inspection of the offspring outcomes considered 123 to potentially influence welfare yielded the following: behavioural changes; adverse effects on body weight and rate of weight gain at key stages of life; survival itself and relevant changes in physiological state such as the ability to thermo-regulate, immunoglobulin $G$ (IgG) status of the neonate and changes in the HPA axis. Detailed analysis revealed that outcomes could be classified in two groups. In one group $(n=83)$, the outcomes were largely directly relevant to neonatal survival and included the ability to thermo-regulate and behavioural indicators of both lamb vigour and ewe-lamb bonding. These studies formed the subject matter of the previous review (Rooke et al 2015). The second group which included behavioural responses together with studies which measured some aspect of HPA function potentially relevant to welfare are considered in this review $(n=21 ; 6$ studies contained subject material relevant to both reviews).

\section{Classification of subject matter for review}

135 Studies were initially classified according to the prenatal treatment applied using the nine 136 hazard categories identified by Arnott et al (2012). In the current review, nutrition; social 
environment, husbandry practices; environmental parameters; infectious environment and maternal health; and artificial challenges (involving exogenous manipulation of HPA axis function) were relevant. Because of the relatively small number of studies, the prenatal treatments were classified as (a) nutritional (N; either under- or over-nourishment); (b) stress (S, whether behavioural or physiological) or other $(\mathrm{O})$.

The offspring outcomes were classified as either physiological or behavioural responses to challenge. Physiological outcomes were classified as either (a) changes in baseline adrenocorticotropic hormone (ACTH) or cortisol concentrations which could be considered as indicators of chronic stress status in contrast to assessment of HPA axis responsiveness to challenge with either: corticotropin-releasing hormone $(\mathrm{CRH})$ plus arginine vasopressin (AVP); ACTH; or social isolation which could be considered as responses to acute stress. Responses were measured by changes in plasma ACTH and cortisol concentrations. Changes in ACTH and cortisol concentrations in response to CRH and AVP are indicative of both pituitary and adrenal responsiveness whereas cortisol response to ACTH specifically quantifies adrenal responsiveness.

152 Behavioural outcomes measured were classified into those that assessed either emotional 153 reactivity or cognitive flexibility. Emotional reactivity outcomes were measured as either responses to novel environments (isolation; novel arena or confinement in a weight crate) or to novel stimuli (novel object; startle stimulus or human proximity). Cognitive flexibility outcomes were measured, for example, by the ability of the offspring to learn that the 157 position of a food reward in a T-maze had changed, usually quantified by how many attempts the offspring required to complete two consecutive runs successfully.

\section{Results}


The studies which make up the subject matter of the review are summarized in Table 1 and are grouped as: alterations to maternal nutrition $(\mathrm{N} 1-\mathrm{N} 12)$; exposure of the ewe to behavioural or physiological stress $(\mathrm{S} 1-\mathrm{S} 6)$; others (O1 to $\mathrm{O} 3$ ) which included the potentially toxic effects of para-chloro benzoates and bacterial lipopolysaccharide. In general, the nature of the treatment imposed on the ewe (Table 1) varied within each of the three groups in regard to both timing and severity as did the age at which responses were assessed (ranging from 1 to 36 months in age). Because of the range in ages at which responses were measured, the maturity of offspring studied ranged from weaning to the mature adult. Therefore, the terms young sheep or offspring rather than lamb will be used from here onwards. Across the studies (Tables 2 to 6 describe outcomes for each of the response types), gestation treatments imposed on the ewe produced significant changes in offspring response in 47 out of $71(67 \%)$ of the outcomes. When these outcomes were separated into physiological (Tables 2 and 3) and behavioural (Tables 4 to 6), fewer significant responses were noted for physiological $(55 \%, 21$ of 38) than behavioural $(84 \%, 26$ of 33) outcomes (Chi square, 4.0; $\mathrm{P}<0.05$ ). Overall therefore, stress treatments imposed on the ewe did induce changes in behavioural and physiological outcomes in the young sheep and behavioural responses may be more sensitive indicators than physiological responses.

Table 1 near here

\section{Physiological outcomes}

Chronic responses of the young sheep were defined as changes in baseline (pre-test) cortisol or ACTH concentrations (Table 2). There were few differences in baseline hormone concentrations when ewes were under-nourished. Only in the study of Bloomfield et al (2003) did offspring cortisol and ACTH concentrations change as a result of maternal undernutrition and indeed the decrease in cortisol only occurred when severe undernutrition 
was applied to the ewe for a short period of time (10 days) in late gestation. Other studies in which ACTH was increased by undernutrition occurred only in males (Gardner et al 2006; Oliver et al 2012) at 12 and 18 months of age respectively and thus, their practical impact would be limited because most male lambs would have been sent for slaughter at a younger age. Additionally, most studies were carried out with intact males and therefore there must be doubt over their application to castrates. When ewes were treated with betamethasone (Sloboda et al 2002), dexamethasone (Long et al 2013) or isolated at weekly intervals (Roussel et al 2004), all in late gestation, then responses were more pronounced. Possibly, therefore timing and nature of challenge is important as offspring basal hormone concentrations were only perturbed when the challenges were (a) applied in late gestation (after 100 days) and (b) acute (including severe UN for 10 days, Bloomfield et al 2003). The study of Long et al (2013) is notable as there were increases in cortisol concentration not only in young sheep born to ewes administered a single dose of dexamethasone (F1 generation) but were also inherited and exhibited by their progeny (F2 generation).

8

A different pattern of response was noted when young sheep were acutely challenged with CRH/AVP or cortisol to assess HPA function (Table 3). There was little evidence for differences due to treatment in offspring cortisol concentration to either ACTH or a behavioural challenge. However, the studies of Long et al $(2010,2012)$ are notable again as the only studies in which CRH/AVP, ACTH and behavioural challenges were applied to the same groups of young sheep. Although the pattern of response differed between studies (probably because different nutritional treatments were imposed upon the ewe), offspring responses to physiological challenge differed from those to social isolation. 
Most studies assessed the effect of CRH/AVP challenge on offspring HPA axis function.

210 Changes in HPA axis outcomes were noted in 7 of 9 studies; however, both increases and

211

212

213 decreases in ACTH and cortisol response were noted. This variability in response is likely in part due to the age at which the animals were tested. Sloboda et al $(2002,2007)$ re-tested the same young sheep whose dams had been challenged with betamethasone in late gestation at 6, 12, 24 and 36 months of age. While there was no effect of treatments imposed on responses to CRH/AVP challenge at 6 months of age, at 12 months of age, maternal betamethasone administration increased offspring cortisol response but at 24 months of age an increase in ACTH responsiveness and at 36 months of age a decrease in cortisol response was recorded; thus HPA function as defined by response to CRH/AVP challenge was clearly dependant upon the age of the animal at test. Finally, Long et al (2013) reported decreases in ACTH and cortisol response to CRH/AVP challenge in both the daughters and granddaughters of ewes challenged with dexamethasone.

\section{Behavioural outcomes}

\section{Emotional reactivity}

Overall, in 9 of the 10 studies listed in Tables 4 and 5, young sheep who were exposed to prenatal treatments exhibited responses to behavioural challenge; the exception being the study of Chadio et al (2007). The hypothesis most commonly stated in these studies was that prenatal treatments increased emotional reactivity, further interpreted as increased fearfulness. In the studies reviewed a consistent pattern does not emerge. The two practically important prenatal treatments, undernutrition and imposition of various stressors on the ewe had different characteristics. Undernutrition was in general applied continuously for more 
than 30 days and from an early stage of gestation. This contrasted with prenatal stress treatments which were imposed in the last third of gestation and although an individual treatment may have been imposed at regular intervals (weekly), each individual challenge was applied typically for only an hour or less, with this acute exposure differing from the chronic (long-term) nature of undernutrition. Within prenatal stress treatments, different treatments probably imposed different severities of challenge. For example, Roussel-Hachette et al (2008) considered that isolation and transport of the ewe was more severe than isolation alone, while Coulon et al (2015) concluded that different stress treatments applied randomly were a more severe challenge than the same stress treatment applied at regular intervals (e.g. Roussel-Hachette et al 2008). Finally the nature of the control treatment may be important when interpreting across different studies: Coulon et al (2011) employed a positive control (gentle handling of the ewe), while the controls in most other studies consisted of no stress treatment.

The effects of undernutrition on offspring emotional reactivity were not consistent across studies. Erhard et al (2004), in the most detailed study, found evidence for increased emotional reactivity in offspring of under-nourished ewes; treatment lambs took longer to approach a novel object and in males only, activity was increased when confined in a weigh crate after exposure to a sudden stimulus. Simitzis et al (2009) however reported no differences and both Corner et al (2005; reduction in high pitched bleats in a novel arena) and Hernandez et al (2010; reduction in escape attempts during social isolation) interpreted the behavioural changes they observed as reductions in emotional reactivity. 
When prenatal stress treatments were applied,, there were indications of changed emotional reactivity. Prenatal stress treatments, at 8 months of age, increased the number of jumps during social isolation, the time spent in proximity to and sniffing a novel object and activity after exposure to a startle stimulus (Roussel et al 2004). In Roussel-Hachette et al (2008), prenatal stress treatment reduced the number of lambs which produced high- pitched bleats in a novel arena test but increased the time lambs spent close to an umbrella used as a startle stimulus. Coulon et al (2011) compared gentle and aversive maternal handling treatments and concluded from an increase in passive responses (reduced locomotor activity and vocalization) in a human approach test and increased flight distances in response to a novel object / startle stimulus that emotional reactivity of young sheep was increased. Similarly when random stress treatments were applied to the dam, Coulon et al (2015) found that prenatal stress increased the time spent distant from the novel object. The differences between the studies of Roussel et al (2004) and Roussel-Hachette et al (2008) and those of Coulon et al $(2011,2015)$ may be that as noted above either the treatment was more severe (Coulon et al 2015) or a positive control was used (Coulon et al 2011).

Other factors that could have influenced response were the severity of the test used to evaluate the young sheep or the stress reactivity of the ewe upon which stress treatments were imposed. Roussel et al (2004) found no differences in offspring response when ewes were selected for low and high reactivity but noted that the ewes habituated to the repeated stress treatments imposed. In contrast, Coulon et al (2015) found that young sheep born to ewes selected for high stress reactivity (based on behavioural and cortisol response to social isolation) were more reactive in human approach and object tests than young sheep born to ewes selected for low reactivity; as the ewe treatments were randomly imposed there was less opportunity for ewes to habituate. Differences in offspring response between different tests 
imposed have also been related to the severity of the test. These have been ascribed to a ceiling effect where responses of both control and treatment offspring to a more severe test masked treatments differences. Thus, Erhard et al (2004) noted greater between-treatment differences when a startle stimulus was applied than in an isolation test and similarly Coulon et al (2014) found responses were greater in a human approach / novel object test than in a social isolation test.

\section{Cognitive flexibility}

Table 6 near here

Table 6 summarizes four studies which tested aspects of cognitive flexibility of young sheep born to ewes exposed to different treatments. Since the methods used to test the offspring whose dams had been under-nourished (Erhard et al 2004; Hernandez et al 2009; T-maze) differed from those whose mothers had been exposed to stress treatments (Coulon et al 2011, 2015; maze with fixed blind alleys), then responses differed between studies. For undernutrition, Erhard et al (2004) reported a sexually dimorphic response where male sheep born to under-nourished ewes were slower to learn a reversal task than control males but there were no differences between females.

However, Hernandez et al (2009) found no differences between treatment groups, but at 6 months of age, females were quicker to learn than males. Similarly while Coulon et al (2011) found no differences in cognitive ability between groups, Coulon et al (2015) found that young sheep whose dams had been exposed to stress were slower to complete a maze test both during learning the maze and upon subsequent re-test. In a test of judgment bias, Coulon et al (2015) also concluded that young sheep whose dams had been exposed to stress had a more pessimistic bias than control sheep and suggested that this could indicate a poorer state 
of welfare. In contrast to emotional reactivity, offspring of high emotional reactivity ewes were not different in cognitive flexibility to those from low emotional reactivity ewes.

\section{Discussion}

\section{Animal welfare implications of prenatal challenges in sheep}

In the current review, the responses of young sheep from approximately weaning to maturity, after exposure of ewes to challenge during pregnancy, have been summarised. As the focus of the review is on the offspring, the consequences of pregnancy challenges for the dam which are an important welfare concern are not discussed here. Overall there were lasting consequences of maternal challenges for the offspring, despite the variety of challenges imposed on the ewe and the variability of the timing and nature of the tests imposed on the young sheep. The key question for this review is whether these responses have implications for the welfare of the offspring throughout their lifespan and indeed for their own progeny. In assessing welfare implications, the conclusions of the current review cannot be viewed in isolation but must be integrated with the conclusions of the preceding review which addressed responses of the lamb from birth to weaning (Rooke et al 2015). The question of whether prenatal insults increase the risk of adverse welfare outcomes in commercial sheep flocks also requires that some consideration is given to likely exposure scenarios. Applications of risk assessment to animal welfare issues are complex (Smulders \& Algers 2009; EFSA 2012, 2014) and are often hampered by a lack of relevant data. Put most simply a risk assessment requires information on two aspects. Firstly, the characterisation of the biological effect that any identified and defined hazard has on a target population, and secondly, the extent of exposure of that population to the hazard. In relation to gestation treatments, hazards can be viewed as being applied to two target populations; the ewe and her 
323 developing fetal progeny. This review, and the previous one (Rooke et al 2015), reveal the current level of understanding of the first issue (hazard effects).

\section{Exposure to hazards}

326 Overall, the existing literature provides only very weak understanding of hazard effects. In relation to the second (exposure), remarkably little is known about the severity and exposure prevalence of putative hazards for pregnant ewes. This means that it is only possible to speculate about exposure scenarios. Because of the seasonality of herbage growth, breeding ewes kept outdoors in winter in temperate production systems (Robinson et al 2002) are likely to experience periods of undernutrition in early to mid gestation. Droughts will have similar effects in other production systems. However in the UK, nutrition is normally increased in late gestation by either housing and feeding ewes supplementary feed or by timing pregnancy such that increased nutritional demands in late gestation are met by increased pasture availability in spring. Undernutrition which was severe in nature and which was applied late in gestation would not normally be encountered in practice in the UK; the most likely scenario would be extreme weather events such as snowfall or flooding which would prevent access to grazing thus causing acute undernutrition. Ewes encounter a variety of aversive events during pregnancy, the frequency and severity of which are dependant upon individual farm management. These events include: movement and handling using sheep dogs to unfamiliar grazing or housing indoors; unfamiliar housing itself; mixing with unfamiliar ewes; transport; restraint and social isolation; shearing. The number of different aversive event types encountered will vary depending on the system. For example, ewes maintained outdoors throughout gestation will be exposed to fewer aversive events imposed by management than ewes housed in late gestation. However, the very nature of farm management means that to the ewe some aversive events are unpredictable and therefore 
ewes would be unable to habituate to them. Thus of the protocols used to impose stress treatments on ewes, the random protocol described by Coulon et al (2014) more closely resembles that which would be encountered in practice although it is unlikely that ewes would be exposed to all the events described by Coulon et al (2014). The protocols used previously by Roussel et al (2004), Roussel-Huchette et al (2008) and Coulon et al (2011) in which the same aversive treatment was repeated at weekly intervals, would have the potential for habituation. An exposure scenario which has not been addressed in the review for practical reasons is that of disease, although offspring responses after exposure of the ewe to para-chlorobenzoates and lipopolysaccharides (Fisher et al, 2010; Gutleb et al, 2011) do highlight the importance of stressors other than undernutrition, housing and management practices.

The reports considered in this review do encompass the relevant target population and exposure scenarios. However, since in practice, the ewe is likely to experience more than one exposure scenario (e.g. both undernutrition and handling) then the absence of studies, which have examined interactions between different exposure scenarios, although necessary to understand the effects of individual exposure scenarios, is an important omission.

\section{Relevance and quality of data}

In the risk assessment process, the identification of relevant data is critical. In this review, the tests employed on young sheep could be broadly divided into two classes: measurement of either physiological or behavioural responses. Since, physiological responses are measured to investigate mechanistic relationships and report changes in selected (but relevant e.g. the HPA axis) body systems, then, first, the responses of many body systems which may be relevant are not reported and secondly, using specific tests precludes any measurement of 
integrated responses by the animal. Given that behaviour reflects an integration of neurobiological and endocrine changes, it is likely that behavioural tests will be more relevant to assessing animal welfare. It was indeed found that behavioural tests detected more differences in response between treatments than physiological tests, likely for the above reasons and also because many behavioural outcome tests are typically performed. Therefore, more weight should be given to behavioural responses of the offspring in assessing welfare outcomes, but this also requires a clear hypothesis-driven rationale for test selection.

The most important variables in interpreting the relevance of responses to welfare are the age at which the young sheep is tested and its gender. The age of the animal at test is important as plasticity of response was noted in studies where offspring were tested across a range of ages (Sloboda et al 2002, 2007; Chadio et al 2007; Oliver et al 2012). Tests should therefore be carried out at ages relevant to expected major welfare challenges. The welfare challenges expected will differ and will be largely dependant on the fate of the young sheep. The majority of males will be destined for slaughter at around 6 months of age and the major challenges encountered by them will be weaning, subsequent management (e.g. housing for fattening), transport to the abattoir and slaughter. Thus for this group of young sheep, tests carried out between 3 and 6 months of age are likely to be relevant. The second main group will comprise largely females retained for breeding. For breeding females, major challenges will occur later in life during repeated breeding cycles beginning from as early as 6 months of age but more likely 18 months of age; therefore tests later than 6 months of age are more relevant. The type of test and direction of response is important in this context. The responses reported in Tables 4 and 5 for emotional reactivity are largely interpreted in relation to fearfulness with those tests involving social isolation being considered to be reliable indicators of fearfulness (Forkman et al 2007). Increased reactivity is usually interpreted as 
increased fearfulness but interpretation of reduced reactivity is more ambiguous being alternatively attributed to either reduced fearfulness or an increase in passive fear response. For young sheep, the major adverse welfare relevant response is likely to be increased fearfulness in response to the situations noted above. In the papers reviewed, only five tested young sheep at the relevant time. When ewes had been previously undernourished (Chadio et al 2007; Simitzis et al 2009; Hernandez et al 2009, 2010), a significant response, decreased escape attempts by the offspring was observed by one study (Hernandez et al., 2010). Thus there is little evidence for increased fearfulness as a result of chronic maternal undernutrition when tested at an appropriate age. In response to stressors imposed on the ewe, Roussel et al (2004) and Roussel-Huchette et al (2008) did not find a consistent pattern of change. As pointed out by Coulon et al (2015) the stress protocols imposed allowed the possibility of 405 habituation by the ewe and this should be taken into account in interpreting these studies. Further, in all the above studies, males had not been castrated and therefore the relevance of the results can be questioned as many males destined for slaughter will be castrated. Thus overall, current evidence does not suggest increased fearfulness in young sheep destined for slaughter as a result of maternal stress imposition, although this conclusion must be heavily qualified because of the small number of studies carried out at the relevant age and the inherent limitations of the studies.

412 For breeding ewes, especially when grazing, increased emotional reactivity may not be an adverse consequence of prenatal stress as it may enhance the ability of the ewe to deal with challenges such as predators in the grazing environment, although as discussed above for the young sheep increased reactivity may not be an advantage when the ewe is exposed to novel environments and challenges such as housing and transport. Considering responses measured

417 at the relevant age (more than 12 months in age; Erhard et al 2004; Corner et al 2005; Chadio 
et al 2007; Hernandez et al 2009, 2010) and only responses for female, there were few significant responses when the dam was under-nourished. Thus, there is little evidence for adverse effects of undernutrition on emotional reactivity. Only Roussel et al (2004), measured responses of offspring at a relevant age in response to maternal stress challenges and recorded an increase in emotional reactivity at 8 months of age. Overall therefore, undernourishment of the ewe appeared to have little adverse consequences for young sheep or breeding females but there was insufficient evidence to make any conclusions in respect of stress challenges imposed on the ewe as only offspring of betamethasone-challenged ewes were tested at the relevant age (Sloboda et al 2007; Long et al 2013). One factor that future research should consider, is the inherent stress responsiveness of the ewe subjected to pregnancy challenges as Coulon et al (2015) found that reactivity of young sheep was increased when the dam was classified as having high stress responsiveness. It is possible also that since Long et al (2013) found that basal cortisol concentrations were increased in the grand-daughters of ewes exposed to dexamethasone, that high stress responsive ewes (Coulon et al 2015) may themselves have been exposed to stress-related events during pregnancy.

\section{Suggestions for future research work and strategies}

435 Overall it is clear that prenatal challenges, either in the form of sub-optimal maternal nutrition or maternal stress have the potential to alter, after weaning, aspects of biology that could have implications for welfare. A similar conclusion was drawn following a review of the same literature in relation to pre-weaning lamb outcomes (Rooke et al 2015). However, in many studies it is difficult to draw clear conclusions in relation to the relative welfare status

440 of prenatally challenged animals versus controls. As it stands now, the research literature in this area does not form a solid basis on which advice to farmers could be based. Partly this is 
442 of course because the field is relatively young and direct practical relevance is often not the

443 primary motivation of those conducting the study. Based on these reviews, along with others

444 recently conducted in cattle (Arnott et al 2012), poultry (Dixon et al 2016) and pigs (Otten et

445 al 2015), where similar issues exist, it is possible to provide some suggestions for a way

446 forward. These relate to: i) the choice of treatments, ii) the choice of outcome measures and

447 iii) possible factors that may modify the effects of prenatal challenge on welfare outcomes.

\section{$448 \quad$ Choice of treatments}

449 Work in this area is conducted for two reasons. Firstly, many studies are used to examine basic biology or to inform human relevance. Secondly, studies are conducted to inform considerations of sheep health, welfare and production in commercial practice. The former is much more common, whilst the latter is more useful from an applied perspective. Basing treatments on practically relevant factors runs the risk that the differences between treated and control animals will be too small for statistical significance to be achieved. However, such a finding adds valuable information about animal management and welfare outcomes. The reality is that such 'negative findings' may be harder to publish and do little for the career progression of the researchers involved. However, a good example from recent work with applied relevance (not included in the current review because neonatal outcomes were measured) is that of Averós et al (2015) who kept ewes at three different stocking densities (1, 2 or $3 \mathrm{~m}^{2}$ per ewe) during gestation and examined the impact of this housing on progeny. Although main effects of stocking density were not significant there were interactions between maternal stocking density and post-natal stress (early separation from dam) such that negative effects of post-natal stress on the offspring were exacerbated by reduced stocking density. 
Beyond the specific choice of treatment, the general lack of attempted replication is an important problem. Demonstration of the repeatability of a finding is the cornerstone of science, yet prenatal stress studies are rarely conducted in the same way twice, and this greatly limits the robustness of conclusions about the reproducibility or generalizability of findings. As with other areas of research (Ioannidis 2005) many of the findings will likely be false. Indeed, Ioannidis (2005) identified characteristics of a research field that increase the likelihood of individual findings being false, and several of these are potential problems in the field of prenatal stress and animal welfare, including: small studies, small effect sizes, a large number of tested relationships and a high level of flexibility in study design, choice of outcome and methods of analysis. There are likely to be various structural and institutional factors which limit attempts at replicating key findings. Funding bodies and journals are not keen on studies which repeat other work, indeed a replication study can even be criticised on ethical grounds, and career progression is similarly not rewarded by studies that confirm previous findings. This means that conclusions are often drawn on the findings of single studies. These conclusions are particularly precarious in light of the fact that prenatal stress studies often measure multiple outcomes, with statistical accounting for this being rare.

Despite the fact that the ewe is likely to encounter multiple stressors during pregnancy, for example undernutrition and handling, none of the reviewed studies investigated interactions between nutrition and stressors. Further while Rooke et al (2015) found no disease-related studies, the one study reported here (Fisher et al 2010) did report changes in lamb physiology following maternal exposure to endotoxins. Both these areas (interactions between stressors and responses to disease challenge) are worthy of further experimentation. 
Prenatal stress studies often involve measurement of many different outcomes, across various

489

490

491

492

494

495

496

497

498

499

500

501

502

503

504

505

506

507

508

509

510 areas of biology. Across the literature as a whole there is a lack of consistency in choice and application of outcome measures. Even where the same parameter is assessed individual studies often vary in the exact approach taken. This is particularly notable in relation to tests of emotionality, where unlike the situation in rodents where tests are generally highly standardised (e.g. open field, elevated-plus maze) there is still substantial variability in test parameters, including arena size and design, and also the nature of outcome measures recorded. Furthermore, there is also a limited degree of prior validation work which allows for variable interpretation of these outcome measures. Another common issue is that many outcome measures are not measured at multiple time points either in the same or different cohorts of animals. This means that the time course of biological changes induced by prenatal challenge is uncertain. A broader issue, which hampers clear animal welfare conclusions, is that individual measures are rarely integrated into some clear understanding of whether the welfare state of the animals involved is overall better or worse as a consequence of the experiences of their mother. Even if it is believed that a physiological or behavioural measure assessed does indeed represent altered emotionality, it is often not clear what the implications of such alterations are for the lifetime welfare of affected animals.

\section{Experimental design factors which may modify offspring outcomes from ewe treatments}

\section{Variable postnatal environments}

Whilst discussing experimental design issues in developmental plasticity studies Groothuis and Taborsky (2015) noted that most theoretical frameworks for understanding prenatal effects rely on a comparison of outcomes under different postnatal conditions. Yet such a comparison is almost never made in research studies involving captive species and animal 
511 welfare issues. In interpreting the studies reviewed one must consider that the welfare

512 relevance of any change in responsiveness may be situation-specific. Thus increased

513 responsiveness in an environment that induces fear and changed HPA axis responsiveness

514 may not have adverse consequences for welfare where the sheep may be exposed to

515 predation, e.g. in a hill environment, but will be relevant in situations such as transport,

516 lairage or slaughter of the animal. Similarly it may be necessary to distinguish between

517 responses which arise from permanent programming of the HPA axis from those which are

518 expressions of developmental flexibility. Whilst for some species, such as pigs, where the

519 range of environments encountered under production conditions is relatively narrow, sheep

520 are managed in different systems, varying from a semi-wild extensive existence to a more

521 intensive lowland system. Changes that are seen in a research context in housed animals may

522 actually be neutral or even beneficial in an extensive setting.

\section{Maternal effects}

524 In risk assessment terms, it is important to consider whether different ewe breeds or ages can

525 be considered as the same or different target populations for the purposes of drawing 526 conclusions about animal welfare impact. Over 100 different breeds of sheep are used in the 527 UK alone (EBLEX 2014) and this range would be extended by consideration of different 528 countries. These breeds vary widely in their productivity and reproductive characteristics, as 529 well as in key aspects of their health, overall robustness and behaviour. Yet it is rare (with 530 some exceptions: Burt et al 2007; Rooke et al 2010) that studies attempt to expose different 531 breeds to the same treatment. A very tentative conclusion from these studies is that animals 532 selected for lean tissue growth are more sensitive to prenatal effects as the birth-weight of 533 lambs born to the selected breed in each study was reduced to a greater extent by under- 
nutrition of the ewe. However, more direct testing of this in future studies would be welcome and an important contribution to elucidating the true industry relevance of this area.

536 Within breeds, differences between ewes in reactivity may also be important determinants of

537 response although evidence is not consistent. While Roussel et al. (2004) found no effect of 538 maternal reactivity on offspring response, Coulon et al. (2014) reported that pre-natally 539 stressed offspring of high emotional reactivity ewes were more affected. These differences in 540 response may be related to either breeds used or the methods used to characterize the ewes.

541 From a practical perspective another factor which may alter the effects of a standard 542 challenge is maternal parity. Parity effects could occur in two different ways. Firstly it is 543 possible that previous experience has a mediating effect on how ewes respond to 544 environmental factors. For instance, younger ewes may find handling and housing more 545 stressful during their first pregnancy compared to later. Secondly, body reserves may differ 546 over several breeding seasons altering the impact of a standard level of nutrition. Finally, 547 there are well known effects of parity on maternal care (Dwyer and Smith 2008; Munoz et al 548 2009). As noted above (in relation to variable ewe temperament: Coulon et al 2015) and 549 previously (e.g. body reserves: Rooke et al 2015), other types of variation in ewe biology will 550 likely modulate the impact on fetal lambs.

\section{Animal welfare implications and conclusion}

552 The data gathered together here and in a related review (Rooke et al 2015) suggest, as expected from other species, that the nutrition and stress state of pregnant ewes can effect many aspects of their progeny's biology, at birth and throughout their life. In some cases these changes may even carry-over into subsequent generations. Furthermore, some of the identified changes clearly have implications for animal welfare. However, detailed analysis 
of the literature shows several deficiencies in the field as a whole which greatly limit the ability to i) draw conclusions about how welfare may be affected by prenatal challenges in commercial sheep, or ii) suggest ways that these effects could be avoided, or even how maternal treatment during gestation might contribute to improving the welfare of farmed sheep. Suggestions have been made relating to how experimental designs could be improved to aid translation to applied relevance. Particularly in respect of both behavioural and physiological outcomes, there is a need for measures that can be integrated to give a global picture of offspring welfare (i.e. a stated conclusion that progeny welfare is overall better or worse for the animals concerned).

\section{Acknowledgments}

We gratefully acknowledge funding from the UK Department for Environment, Food and Rural Affairs (Defra, Project AW0509: Early environment effects on animal welfare, health and productivity) and the Scottish Government (SPASE Module 2: Effects of early environment on behaviour, reproduction, welfare and product quality of livestock.

\section{References}

Arnott G, Roberts D, Rooke JA, Turner SP, Lawrence AB and Rutherford KMD 2012 Board invited review: The importance of the gestation period for welfare of calves: maternal stressors and difficult births. Journal of Animal Science 90: 5021-5034.

\section{Averós X, Marchewka J, de Heredia IB, Zanella AJ, Ruiz R and Estevez I 2015 Space} allowance during gestation and early maternal separation: effects on the fear response and social motivation of lambs. Applied Animal Behaviour Science 163: 98-109. 
Barker DJP, Osmond C, Golding J, Kuh D and Wadsworth MEJ 1989 Growth in utero,

579

580

581

582

583

584

585

586

587

588

589

590

591

592

593

594

595

596

597

598

blood pressure in childhood and adult life, and mortality from cardiovascular disease. British Medical Journal 298: 564-567.

Bloomfield FH, Oliver MH, Giannoulias CD, Gluckman PD, Harding JE and Challis JRG 2003 Brief undernutrition in late-gestation sheep programs the hypothalamic-pituitaryadrenal axis in adult offspring. Endocrinology 144: 2933-2940.

Burt BE, Hess BW, Nathanielsz PW and Ford SP 2007 Flock differences in the impact of maternal dietary restriction on offspring growth and glucose tolerance in female offspring. Society for Reproduction and Fertility Supplement 64: 411-424.

Campbell MLH, Mellor DJ and Sandoe P 2014 How should the welfare of fetal and neurologically immature postnatal animals be protected? Animal Welfare 23: 369-379.

\section{Chadio SE, Kotsampasi B, Papadomichelakis G, Deligeorgis S, Kalogiannis D,} Menegatos I and Zervas G 2007 Impact of maternal undernutrition on the hypothalamicpituitaryadrenal axis responsiveness in sheep at different ages postnatal. Journal of Endocrinology 192: 495-503.

Corner R, Kenyon P, Stafford K, West D, Morris S and Blair H 2005 Does the ewe nutrition during pregnancy affect the behaviour of ewe lambs at 1 and 2 years of age? Proceedings of the New Zealand Society of Animal Production 65: 29-32.

Coulon M, Hild S, Schroeer A, Janczak A and Zanella A 2011. Gentle vs. aversive handling of pregnant ewes: II. Physiology and behavior of the lambs. Physiology and Behavior 103: 575-584. 
599

600

601

602

603

604

605

606

607

608

609

610

611

612

613

614

615

616

617

618

619

620

Coulon MF, Levy C, Ravel R, Nowak S and Boissy A 2014 Mild effects of gestational stress and social reactivity on the onset of mother-young interactions and bonding in sheep. Stress-the International Journal on the Biology of Stress 17: 460-470.

Coulon M, Nowak R, Andanson S, Petit B, Levy F, and Boissy A 2015 Effects of prenatal stress and emotional reactivity of the mother on emotional and cognitive abilities in lambs. Developmental Psychobiology 57: 626-636.

Dixon LM, Sparks NHC and Rutherford KMD 2016 Early experiences matter: a review of the effects of prenatal environment on offspring characteristics in poultry. Poultry Science 95: 489-499.

\section{Donovan E, Hernandez C, Matthews L, Oliver M, Jaquiery A, Bloomfield F and} Harding J 2013 Periconceptional undernutrition in sheep leads to decreased locomotor activity in a natural environment. Journal of Developmental Origins of Health and Disease 4: 296-299.

Dwyer CM and Smith LA 2008 Parity effects on maternal behaviour are not related to circulating oestradiol concentrations in two breeds of sheep. Physiology and Behavior 93: $148-154$.

English Beef and Lamb Executive (EBLEX) 2014. EBLEX 2014. The breeding structure of the British sheep industry 2012. Agriculture and Horticulture Development board (AHDB): Kenilworth, Warwickshire.

Erhard HW, Boissy A, Rae MT and Rhind SM 2004 Effects of prenatal undernutrition on emotional reactivity and cognitive flexibility in adult sheep. Behavioural Brain Research 151: $25-35$. 
Erhard HW and Rhind SM 2004. Prenatal and postnatal exposure to environmental

622

623

624

625

626

627

628

629

630

631

632

633

634

635

636

637

638

639

640

641

642

643

pollutants in sewage sludge alters emotional reactivity and exploratory behaviour in sheep.

Science of the Total Environment 332: 101-108.

European Food Safety Authority (EFSA) Panel on Animal Health and Welfare (AHAW) 2012 Guidance on risk assessment for animal welfare. EFSA Journal 10: 2513, 30 pp.

European Food Safety Authority (ESFA) Panel on Animal Health and Welfare (AHAW) 2014 Scientific opinion on the welfare risk related to the farming of sheep for wool, meat and milk production. EFSA Journal 12: 3933, 128pp,

Fisher RE, Karrow NA, Quinton M, Finegan EJ, Miller SP, Atkinson JL and Boermans HJ 2010 Endotoxin exposure during late pregnancy alters ovine offspring febrile and hypothalamic-pituitary-adrenal axis responsiveness later in life. Stress-the International Journal on the Biology of Stress 13: 335-343.

Ford S and Long N 2012 Evidence for similar changes in offspring phenotype following either maternal undernutrition or overnutrition: potential impact on fetal epigenetic mechanisms. Reproduction Fertility and Development: 105-111.

Forkman B, Boissy A, Meunier-Salauen MC, Canali E and Jones RB 2007 A critical review of fear tests used on cattle, pigs, sheep, poultry and horses Physiology and Behavior 92: $340-374$.

\section{Gardner DS, Van Bon BWM, Dandrea J, Goddard, PJ, May SF, Wilson V, Stephenson}

T and Symonds ME 2006 Effect of periconceptional undernutrition and gender on hypothalamic-pituitary-adrenal axis function in young adult sheep. Journal of Endocrinology 190: 203-212. 
644 Gluckman PD and Hanson MA 2004 Developmental origins of disease paradigm: A 645 mechanistic and evolutionary perspective. Pediatric Research 56: 311-317.

646 Groothuis TGG and Taborsky B 2015 Introducing biological realism into the study of 647 developmental plasticity in behaviour. Frontiers in Zoology 12(Suppl. 1: S6

648 Gutleb AC, Lilienthal H, Erhard HW, Zimmer KE, Skaare JU and Ropstad E 2011 649 Effects of pre- and postnatal polychlorinated biphenyl exposure on emotional reactivity 650 observed in lambs before weaning. Ecotoxicology and Environmental Safety 74: 1396-1401.

Hernandez CE, Harding JE, Oliver MH, Bloomfield FH, Held SDE and Matthews LR 2009 Effects of litter size, sex and periconceptional ewe nutrition on side preference and cognitive flexibility in the offspring. Behavioural Brain Research 204: 82-87. of sex, litter size and periconceptional ewe nutrition on offspring behavioural and physiological response to isolation. Physiology and Behavior 101: 588-594.

657

Ioannidis JPA 2005 Meta-analysis in public health: potentials and problems. European Journal of Public Health 15: 60-61.

King S, Dancause K, Turcotte-Tremblay A-M, Veru F and Laplante DP 2012 Using natural disasters to study the effects of prenatal maternal stress on child health and development. Birth Defects Research (Part C) 96: 273-288.

Long NM, Nijland MJ, Nathanielsz PW and Ford SP 2010 The effect of early to midgestational nutrient restriction on female offspring fertility and hypothalamic-pituitaryadrenal axis response to stress. Journal of Animal Science 88: 2029-2037. 

Animal Endocrinology 42: 195-202.

668

669

670

671

672

673

674

675

676

677

678

679

680

681

682

683

684

685

Long NM, Ford SP and Nathanielsz PW 2013 Multigenerational effects of fetal dexamethasone exposure on the hypothalamic-pituitary-adrenal axis of first- and secondgeneration female offspring. American Journal of Obstetrics and Gynecology 208: article, 217.e1.

Lumey LH, Stein AD and Susser E 2011 Prenatal famine and adult health. Annual Review of Public Health 32: 237-262.

Luther, JS, Redmer DA, Reynolds LP and Wallace JM 2005 Nutritional paradigms of ovine fetal growth restriction: implications for human pregnancy. Human Fertility 8: 179187.

Munoz C, Carson AF, McCoy MA, Dawson LER, O'Connell NE and Gordon AW 2009

Effect of plane of nutrition of 1-and 2-year-old ewes in early and mid-pregnancy on ewe reproduction and offspring performance up to weaning. Animal 3: 657-669.

\section{Oliver MH, Bloomfield FH, Jaquiery AL, Todd SE, Thorstensen EB and Harding JE}

2012. Periconceptional undernutrition suppresses cortisol response to arginine vasopressin and corticotropin-releasing hormone challenge in adult sheep offspring. Journal of Developmental Origins of Health and Disease 3: 52-58.

Otten W, Kanitz E and Tuchscherer M 2015. The impact of pre-natal stress on offspring development in pigs. Journal of Agricultural Science 153: 907-919. 
686 Robinson JJ, McEvoy TG. Rooke JA 2002 Nutrition for conception and pregnancy. In:

687 Freer M and Dove H (Eds) Sheep Nutrition pp. 189 - 211. CABI Publishing: Wallingford, 688 UK.

689

690

691

692

693

694

695

696

697

698

699

700

701

702

703

704

705

706

Rooke JA, Houdijk JGM, McIlvaney K, Ashworth CJ and Dwyer CM 2010 Differential

effects of maternal undernutrition between days 1 and 90 of pregnancy on ewe and lamb

performance and lamb parasitism in hill or lowland breeds. Journal of Animal Science 88: 3833-3842.

Rooke JA, Arnott G, Dwyer CM and Rutherford KMD 2015 The importance of the gestation period for welfare of lambs : maternal stressors and lamb vigour and well-being. Journal of Agricultural Science 153: 497-519.

Roussel S, Hemsworth PH, Boissy A and Duvaux-Ponter C 2004 Effects of repeated stress during pregnancy in ewes on the behavioural and physiological responses to stressful events and birth weight of their offspring. Applied Animal Behaviour Science 85: 259-276.

Roussel-Huchette S, Hemsworth PH, Boissy A and Duvaux-Ponter C 2008 Repeated transport and isolation during pregnancy in ewes: Differential effects on emotional reactivity and weight of their offspring. Applied Animal Behaviour Science 109: 275-291.

Rutherford KMD, Donald RD, Arnott G, Rooke JA, Dixon L, Mettam J, Turnbull J and Lawrence AB 2012 Farm animal welfare: assessing risks attributable to the prenatal environment. Animal Welfare 21: 419-429

Sargeant JM, Rajic A, Read S and Ohlsson A 2006. The process of systematic review and its application in agri-food public-health. Preventive Veterinary Medicine 75: 141-151. 

EP, Papavlasopoulou EK and Deligeorgis SG 2009 Influence of maternal undernutrition on the behaviour of juvenile lambs. Applied Animal Behaviour Science 116: 191-197. 2016 Epigenetics and developmental programming of welfare and production traits in farm animals. Reproduction, Fertility and Development,28: 1443-1478.

Sloboda DM, Moss TJ, Gurrin LC, Newnham JP and Challis JRG 2002 The effect of prenatal betamethasone administration on postnatal ovine hypothalamic-pituitary-adrenal function. Journal of Endocrinology 172: 71-81. 2007 Prenatal betamethasone exposure results in pituitary-adrenal hyporesponsiveness in adult sheep. American Journal of Physiology-Endocrinology and Metabolism 292: E61-E70.

Smulders FJM and Algers B 2009 Welfare of production animals: assessment and management of risks. Wageningen Academic Publishers:Wageningen, The Netherlands. 
Table 1. Summary of studies included in review giving treatments imposed during gestation on ewes and their timing (days, where day $=0$ is mating) and the age (months) and gender of young sheep (F, female; M male; MC, castrate male) when tested

\begin{tabular}{|c|c|c|c|c|c|}
\hline \multirow[t]{2}{*}{ Study } & \multirow[t]{2}{*}{ Reference } & \multicolumn{2}{|c|}{ Ewe } & \multicolumn{2}{|c|}{ Young sheep } \\
\hline & & Treatment $^{*}$ & Timing during gestation & Age & Gender \\
\hline \multicolumn{6}{|c|}{ Under (UN) or Over (ON) Nutrition } \\
\hline N1 & Bloomfield et al 2003 & $\mathrm{UN}: 0.02$ or 0.04 requirement & $105-115$ or $105-125$ & 30 & $\mathrm{~F}$ \\
\hline $\mathbf{N} 2$ & Erhard et al 2004 & $\mathrm{UN}: 0.5$ requirement & $0-95$ & 18 & $\mathrm{~F}, \mathrm{M}$ \\
\hline N3 & Corner et al 2005 & UN: 0.6 requirement & $64-132$ & 12 & $\mathrm{~F}$ \\
\hline $\mathbf{N} 4$ & Gardner et al 2006 & $\mathrm{UN}: 0.5$ requirement & $1-30$ & 12 & $\mathrm{~F}, \mathrm{M}$ \\
\hline N5 & $\begin{array}{l}\text { Chadio et al 2007; Simitzis et } \\
\text { al } 2009\end{array}$ & $\mathrm{UN}: 0.5$ requirement & $0-30 ; 30-100$ & $2,3,4,5,6,10$ & $\mathrm{~F}, \mathrm{M}$ \\
\hline N6 & Hernandez et al 2009 & $\mathrm{UN}: 0.5$ - 0.8 requirement & $-60-30$ & 4,18 & $\mathrm{~F}, \mathrm{M}$ \\
\hline N7 & Hernandez et al 2010 & UN: 0.5 - 0.8 requirement & $-60-30 ;-60-0 ; 0-30$ & 4,18 & $\mathrm{~F}, \mathrm{M}$ \\
\hline N8 & Long et al 2010 & UN: 0.5 requirement & $28-147$ & 12 & $\mathrm{~F}$ \\
\hline N9 & Wallace et al 2011 & $\begin{array}{l}\text { UN: } 0.75 \text { requirement; } \\
\text { ON: } 2.2 \text { requirement }\end{array}$ & $7-147$ & $9,18,24$ & $\mathrm{~F}, \mathrm{M}$ \\
\hline N10 & Long et al 2012 & ON: 1.5 requirement & $-60-147$ & 20 & $\mathrm{~F}, \mathrm{M}$ \\
\hline N11 & Oliver et al 2012 & $\mathrm{UN}: 0.5$ - 0.8 requirement & $-60-30$ & $4,10,18$ & $\mathrm{~F}, \mathrm{M}$ \\
\hline N12 & Donovan et al 2013 & UN: 0.5 - 0.8 requirement & $-60-30$ & 18 & $\mathrm{~F}, \mathrm{M}$ \\
\hline Stress & & & & & \\
\hline
\end{tabular}




\begin{tabular}{|c|c|c|c|c|c|}
\hline S1 & Sloboda et al 2002, 2007 & Betamethasone & $104 ; 104-125$ & $6,12,24,36$ & $\mathrm{~F}, \mathrm{MC}$ \\
\hline $\mathbf{S 2}$ & Roussel et al 2004 & Isolation (1h ; 2 x weekly) & $112-147$ & 1,8 & $\mathrm{~F}, \mathrm{M}$ \\
\hline \multirow[t]{2}{*}{ S3 } & Roussel-Huchette et al 2008 & Isolation (1h; 2 x weekly) & $115-147$ & 4 & $\mathrm{~F}, \mathrm{M}$ \\
\hline & & Isolation and transport & & & \\
\hline S4 & Coulon et al 2011 & Aversive handling & $115-147$ & 1 & $\mathrm{~F}, \mathrm{M}$ \\
\hline S5 & Long et al 2013 & Dexamethasone & $103-104$ & $16,28,(\mathrm{~F} 2) 6$ & $\mathrm{~F}$ \\
\hline S6 & Coulon et al 2014, 2015 & $\begin{array}{l}\text { Isolation; mixing; transport; dog } \\
\text { handling; sham shearing; delayed } \\
\text { feeding (total } n=16 \text { / ewe) }\end{array}$ & $94-103$ & 1 & $\mathrm{~F}, \mathrm{M}$ \\
\hline \multicolumn{6}{|c|}{ Other } \\
\hline $\mathbf{0 1}$ & Erhard and Rhind 2004 & $\begin{array}{l}\text { Sewage sludge containing } \\
\text { parachlorobenzoates }\end{array}$ & $0-147$ & 5 & $\mathrm{~F}, \mathrm{M}$ \\
\hline $\mathbf{O 2}$ & Fisher et al 2010 & Lipopolysaccharide & $135 ; 135-137$ & 5,18 & $\begin{array}{l}\mathrm{F}, \mathrm{M} \\
\text { (5 mo only) }\end{array}$ \\
\hline $\mathbf{O 3}$ & Gutleb et al 2011 & Parachlorobenzoates & $0-147$ & 1 & $\mathrm{~F}, \mathrm{M}$ \\
\hline
\end{tabular}

* UN and ON are expressed as a proportion of the requirement of the ewe and conceptus for energy. 
Table 2 Changes in basal concentrations of cortisol and ACTH in young sheep whose dams were exposed to gestation treatments (responses are with reference to controls) (Identity of studies given in Table 1).

\begin{tabular}{|c|c|c|}
\hline Study & Cortisol & ACTH \\
\hline N1 & Decrease & Tendency to increase \\
\hline N4 & No difference & Tendency to increase in males \\
\hline N5 & No difference & No difference \\
\hline N7 & No difference & \\
\hline N8 & No difference & No difference \\
\hline \multirow[t]{2}{*}{ N9 } & No difference & Undernutrition: no difference \\
\hline & & $\begin{array}{l}\text { Overnutrition: increase at } 9,18 \\
\text { months }\end{array}$ \\
\hline N10 & Increase & No difference \\
\hline N11 & No difference & Increase in males at 18 months only \\
\hline S1 & $\begin{array}{l}\text { Increase in males at } 12 \text { months } \\
\text { only }\end{array}$ & Increase in males at 24 months only \\
\hline \multirow[t]{2}{*}{$\mathbf{S 2}$} & Increase at 1 month; & \\
\hline & No difference at 8 months & \\
\hline \multirow[t]{2}{*}{ S5 } & Increase in $\mathrm{F} 1$ and $\mathrm{F} 2$ & No difference in F1; \\
\hline & & Increase in $\mathrm{F} 2$, \\
\hline $\mathbf{O 2}$ & No difference & \\
\hline
\end{tabular}


Table 3 Responses of young sheep whose dams had been exposed to gestation treatments to physiological or behavioural challenges. Responses are given as differences in the increase in plasma adrenocorticotropic hormone (ACTH) or cortisol concentration (expressed as area under curve) relative to young sheep from control ewes. Challenges were arginine vasopressin (AVP)/ corticotropin-releasing hormone (CRH); ACTH; or isolation. (Identity of studies given in Table 1).

\section{Challenge}

\begin{tabular}{|c|c|c|c|}
\hline & CRH/AVP & ACTH & Social isolation \\
\hline N1 & $\begin{array}{l}\text { Increase in ACTH } \\
\text { after } 10 \text { but not } 20 \text { day } \\
\text { ewe feed restriction }\end{array}$ & & \\
\hline N4 & $\begin{array}{l}\text { Increase in ACTH and } \\
\text { cortisol in males but } \\
\text { decrease in females }\end{array}$ & & \\
\hline N5 & $\begin{array}{l}\text { Increase in ACTH and } \\
\text { cortisol at } 2 \text { months } \\
\text { old only }\end{array}$ & & \\
\hline N7 & & & Decrease in cortisol \\
\hline N8 & No difference & No difference & Decrease in cortisol \\
\hline N9 & No difference & & \\
\hline N10 & Increase in $\mathrm{ACTH}$ & No difference & No difference \\
\hline N11 & $\begin{array}{l}\text { Increase in ACTH in } \\
18 \text { month old females } \\
\text { only }\end{array}$ & & \\
\hline S1 & $\begin{array}{l}\text { increase in ACTH in } \\
24 \text { month old males; } \\
\text { increase in cortisol in } \\
6,12 \text { month old males } \\
\text { but decrease at } 36 \\
\text { months }\end{array}$ & & \\
\hline S2 & & & No difference \\
\hline S5 & $\begin{array}{l}\text { ACTH and cortisol } \\
\text { decreased in both F1 } \\
\text { and F2 generation }\end{array}$ & No difference & \\
\hline $\mathbf{O 2}$ & & Increase in cortisol & \\
\hline
\end{tabular}


Table 4 Behavioural responses when exposed to a novel environment of young sheep whose dams were exposed to gestation challenges (responses are changes with reference to controls) (Identity of studies given in Table 1).

\begin{tabular}{|c|c|c|c|}
\hline \multirow[b]{2}{*}{ Study } & \multicolumn{3}{|c|}{ Novel environment } \\
\hline & Social isolation & Arena & Weigh crate \\
\hline $\mathbf{N} 2$ & No difference & & Males displayed increased activity in crate \\
\hline N3 & & $\begin{array}{l}\text { Fewer young sheep produced } \\
\text { high-pitched bleats }\end{array}$ & \\
\hline N5 & No difference & & \\
\hline N7 & $\begin{array}{l}\text { Fewer attempts to escape from } \\
\text { enclosure ( } 4 \text { months old only) }\end{array}$ & & \\
\hline $\mathbf{S 2}$ & $\begin{array}{l}\text { Increase in number of jumps ( } 8 \\
\text { months old only) }\end{array}$ & $\begin{array}{l}\text { Less time spent close to arena } \\
\text { entrance }\end{array}$ & \\
\hline S3 & $\begin{array}{l}\text { Increase in number of jumps ( } 1 \\
\text { month old only) }\end{array}$ & $\begin{array}{l}\text { Decrease in number of jumps } \\
\text { ( } 1 \text { and } 3 \text { months old) }\end{array}$ & \\
\hline S6 & $\begin{array}{l}\text { No overall difference due to } \\
\text { prenatal stress. Stress reactivity } \\
\text { of ewe influenced response in } \\
\text { absence of prenatal stress. }\end{array}$ & & \\
\hline 01 & & $\begin{array}{l}\text { Increase in time spent } \\
\text { exploring arena in males only }\end{array}$ & $\begin{array}{l}\text { Increased number of vocalizations and } \\
\text { decrease in activity in crate }\end{array}$ \\
\hline $\mathbf{O 3}$ & & & $\begin{array}{l}\text { Increases / decreases in activity observed in } \\
\text { crate; response depended on } \\
\text { parachlorobenzoate }\end{array}$ \\
\hline
\end{tabular}


Table 5 Behavioural responses, when exposed to a novel stimulus, of young sheep whose dams were exposed to gestation challenges (responses are changes with reference to controls) (Identity of studies given in Table 1).

\begin{tabular}{|c|c|c|c|}
\hline & \multicolumn{3}{|c|}{ Novel stimulus } \\
\hline & Object & Startle & Human \\
\hline $\mathbf{N 2}$ & $\begin{array}{l}\text { Increased latency to } \\
\text { approach object }\end{array}$ & $\begin{array}{l}\text { Locomotion activity increased in } \\
\text { males but decreased in females }\end{array}$ & \\
\hline N3 & & & No difference \\
\hline N5 & No difference & & \\
\hline S2 & $\begin{array}{l}\text { Spent more time close to } \\
\text { object and more time } \\
\text { sniffing object }\end{array}$ & $\begin{array}{l}\text { Increased activity in response to } \\
\text { stimulus ( } 8 \text { months old only) }\end{array}$ & \\
\hline S3 & & $\begin{array}{l}\text { Spent more time within } 2 \text { metres } \\
\text { of object }\end{array}$ & \\
\hline S4 & & $\begin{array}{l}\text { Tendency for increase in flight } \\
\text { distance from stimulus }\end{array}$ & Reduced vocalization \\
\hline S6 & & $\begin{array}{l}\text { Prenatal stress treatment lambs } \\
\text { spent more time distant from } \\
\text { object. Prenatal stress offspring of } \\
\text { high stress reactive ewes spent } \\
\text { less time close to object than } \\
\text { offspring of low stress reactive } \\
\text { ewes; no maternal reactivity effect } \\
\text { in non-stressed offspring }\end{array}$ & $\begin{array}{l}\text { Prenatal stress effects only in offspring of high } \\
\text { stress reactive ewes: presence of human } \\
\text { reduced locomotor activity, vocalization, } \\
\text { exploration. Presence / absence of human did } \\
\text { not change responses in offspring of low stress } \\
\text { reactive ewes. }\end{array}$ \\
\hline 01 & $\begin{array}{l}\text { Increase in time spent } \\
\text { exploring(males only) }\end{array}$ & & \\
\hline
\end{tabular}


Table 6. Behavioural responses relating to cognitive flexibility of young sheep whose dams had been exposed to gestation challenges (responses are changes with reference to controls) (Identity of studies given in Table 1).

\begin{tabular}{lll}
\hline Study and test & Response & Comment \\
\hline T Maze & Initial side preference & $\begin{array}{l}\text { Reduction in right side choice in treatment offspring; only } \\
\text { significant in females } \\
\text { Only male treatment offspring failed to improve learning } \\
\text { speed between reversals }\end{array}$ \\
N6 & Task reversal & $\begin{array}{l}\text { Reduction in left side preference in male singletons; reduction } \\
\text { in right side preference in female twins }\end{array}$ \\
& Task reversal & No differences \\
Blind Maze & Latency to solve & No differences \\
S4 & Re-test response & No differences \\
& & \\
S6 & Latency to solve & $\begin{array}{l}\text { Prenatal stress offspring slower to complete test } \\
\text { Prenatal stress offspring slower to complete test }\end{array}$ \\
\hline
\end{tabular}

